\title{
TURBULENCE INTENSITY EFFECTS ON THE VERTICAL AXIS Wind TURbine STARTING EFFiCIENCY
}

\author{
Ion Mălăel, Valeriu Drăgan,Bogdan Gherman \\ Romanian Research \& Development Institute for Gas Turbines COMOTI \\ 220D Iиliu Maniu Ave., 061126, Bucharest, Romania
}

\begin{abstract}
In this paper, the authors performed a series of numerical analysis using CFD methods for the study of turbulence intensity effects on the efficiency of a wind turbine vertical axis Darrieus type, at the starting point. These analyzes have the tip speed ratio value (TSR) equal to 1 . The solver used is based on pressure and it uses the Simple Method (semi-implicitmethod-pressure-linked-equation). To determine the influence of the turbulence intensity were imposed on border conditions, the intensity values between 1 and 20\%. Finally, are represented variations of moment and power coefficients for a full rotation (0-360 degrees). The magnitude vorticity variation is also presented for all the studied cases.
\end{abstract}

Keywords: VAWT, CFD, Wind, TSR, Turbulence
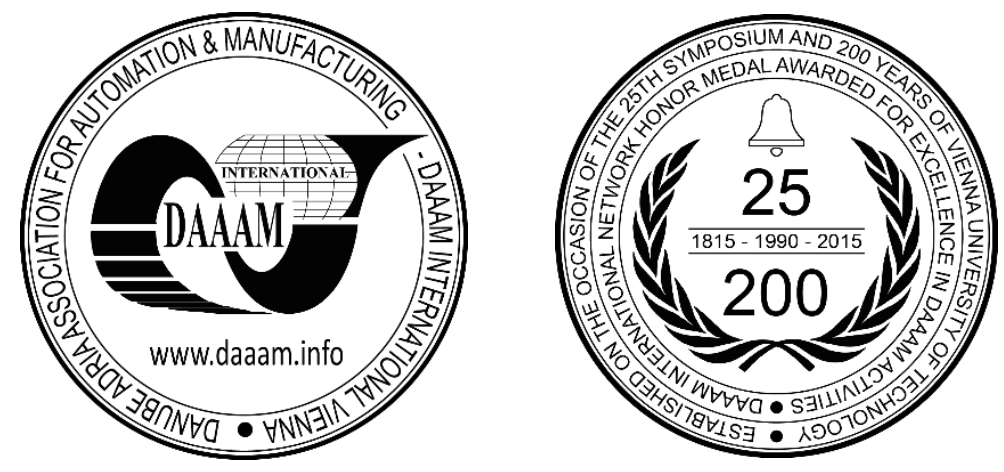

This Publication has to be referred as: Malael, I[on]; Dragan, V[aleriu] \& Gherman, G[eorge] B[ogdan] (2016). Turbulence Intensity Effects on the Vertical Axis Wind Turbine Starting Efficiency, Proceedings of the 26th DAAAM International Symposium, pp.0974-0979, B. Katalinic (Ed.), Published by DAAAM International, ISBN 978-3-90273407-5, ISSN 1726-9679, Vienna, Austria

DOI: $10.2507 / 26$ th.daaam.proceedings. 137 


\section{Introduction}

Because of the current technology, fuel is growing. Which, unfortunately, has negative effects on the environment through $\mathrm{CO} 2$ 's emissions both by the use of liquid and solid fuel? An alternative is represented by renewable energy. An important component of this kind of energy is represented by wind energy.

Although at this time the market is dominated by HAWT, VAWT are starting to catch up also because of its advantages. Among these advantages are its independence from wind direction and the fact that it can also work at lower wind speed values. The flow in such a turbine is entirely non-stationary and is dictated by the phenomenon of dynamic stall [1-2]. Numerous scientific papers are based on the analysis of this phenomenon to determine its effects on the efficiency of a VAWT [3-5].

In determining the the efficiency of a VAWT, we mention the reference works [6-7] where efficiency of a vertical axis wind turbines was determined using models based on "double-multiple-streamtube". The efficiency of a vertical axis wind turbine is influenced by many factors such as solidity, TSR, wind speed, and also the influence of the number of blades on aerodynamic efficiency[8]. Other theories were proposed and used to determine the efficiency of a wind turbine Darrieus type [9] with results which were verified with experimental data obtained in the wind tunnel.

For numerical investigation of the flow in a VAWT, commercial CFD codes using standard methods URANS or LES URANS models can analyze both the non-stationary nature of the flow and turbulence effects [10]. If in the past URANS models were imprecise in the transition zone between laminar and the turbulent regime newelly developed adaptations to the standard SST model, having four transport equations, can also capture transition [11].

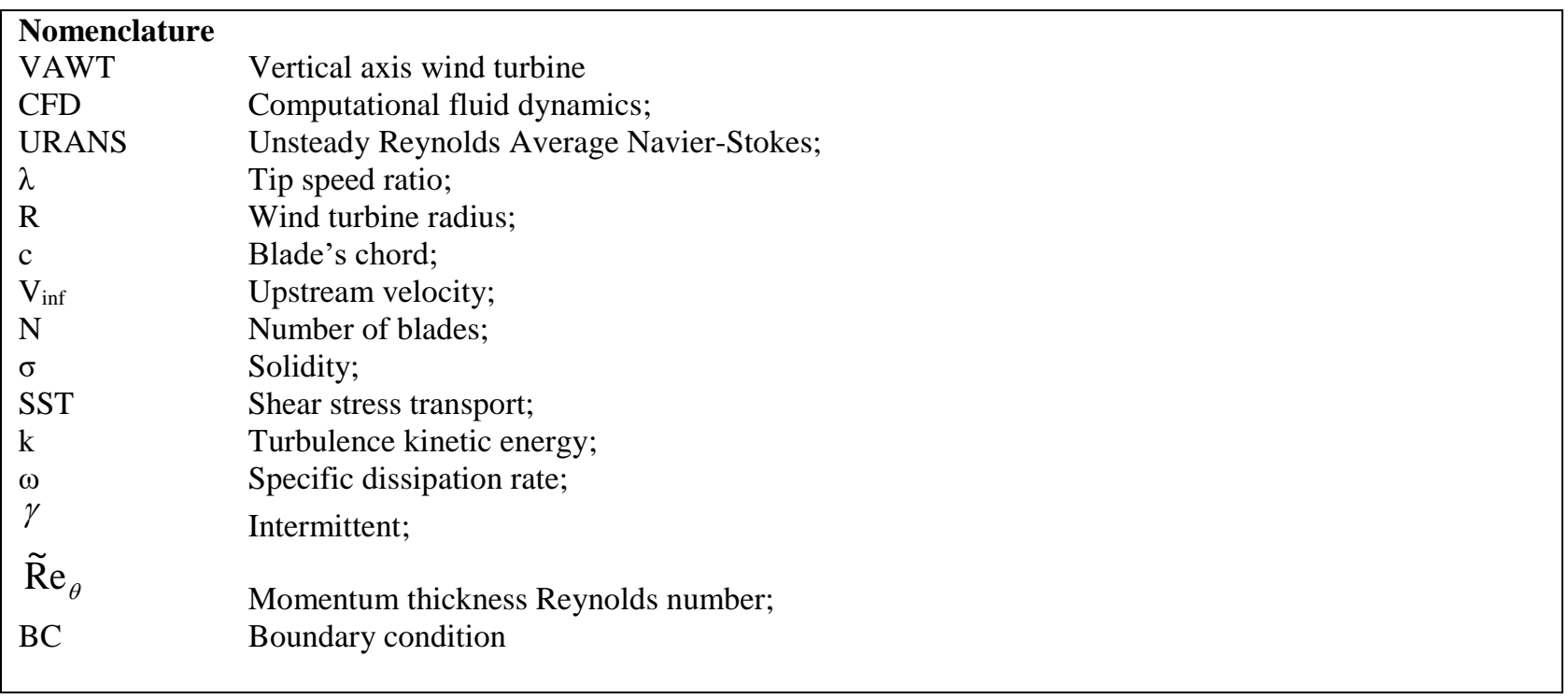

\section{Numerical method}

In this section we present details about the numerical simulations of flow around a Darrieus type vertical axis wind turbine using Ansys Fluent CFD code. First, in Fig.1 is shown the 3D virtual model of the wind turbine along with the two-dimensional computational meshes used for the stationary domain and the rotating domain which containes the blades.

This turbine is designed to generate up to $5.5 \mathrm{~kW}$ power at a wind speed of $8 \mathrm{~m} / \mathrm{s}$. Table 1 shows the geometric parameters of the entire system. Equation (1) was used for the dimensioning the wind turbine rotor. In this way, the characteristic dimensions such as height and rotor diameter were determined. Given that it is desired to have high efficiency values at lowTSRs, the turbine solidity was imposed at 0.5. Thus using equation (2) we determined the aerodynamic chord length of the vertical axis wind turbine blades. For the actual airfoil we chose the NACA 0021 which has a well documented behavior even at post-stall angles of attack and also has been used in previous numerical tests performed by the authors. 

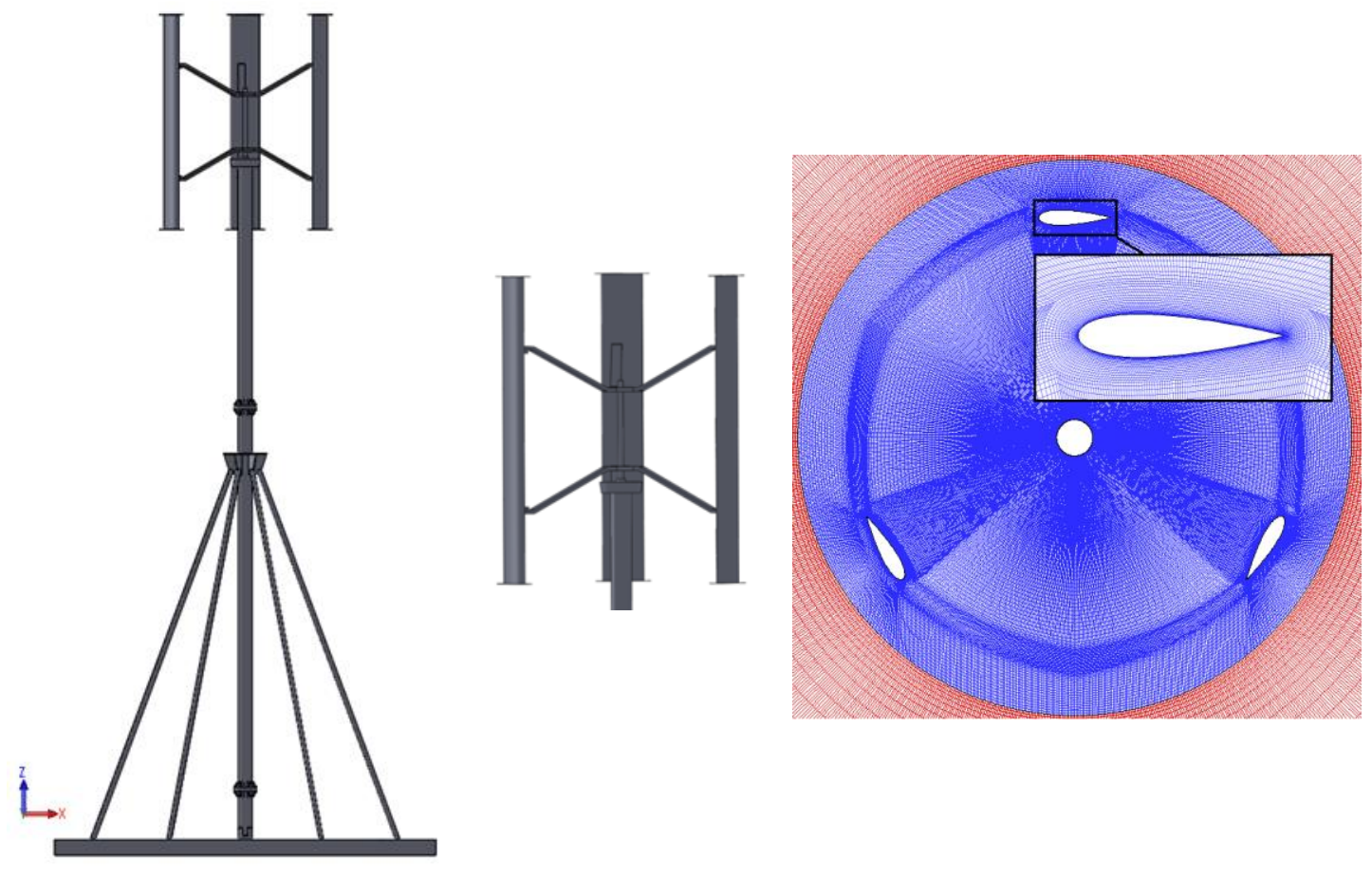

Fig. 1. (a) The VAWT geometry; (b)The mesh for VAWT

$$
\begin{aligned}
& P=\frac{1}{2} \rho S C p V_{\mathrm{inf}}^{3} \Rightarrow S=\frac{2 P}{\rho C p V_{\mathrm{inf}}^{3}} \Rightarrow H, D \\
& \sigma=\frac{N c}{R} \Rightarrow c=\frac{\sigma R}{N}
\end{aligned}
$$

\begin{tabular}{lcc}
\hline & Parameter & Value \\
\hline rotor diameter & $\mathrm{D}[\mathrm{m}]$ & 3.6 \\
Height rotor & $\mathrm{h}[\mathrm{m}]$ & 4.5 \\
Number of blades & $\mathrm{N}[-]$ & 3 \\
Height whole ensemble & $\mathrm{H}[\mathrm{m}]$ & 16 \\
blade chord & $\mathrm{c}[\mathrm{m}]$ & 0.6 \\
\hline
\end{tabular}

Table 1. The turbine features

The computational domain was divided into two subdomains. One rotoric - containing the blades of and the shaft of the wind turbine, and one stationary - representing the farfield. Figure 1 (b) presents the structured mesh created for this set of tests.

For this analysis, an URANS model was used to study the effectsof turbulence intensity on the efficiency of the wind turbine. Thus we chose different values of intensity on the farfield frontier of the computational domain, this is seen as a replacement for the practical case where a turbulence inducing grid or obstacle would typicaly influence the flow upstream.Turbulence intensity values were considered at multiple values between $1 \%$ and $20 \%$.The URANS methods were used in conjunction with the SIMPLE pressure-velocity coupling method. All tests were performed in $2 \mathrm{D}$ with the transition correcting SST turbulence model.

Since the flow at the starting regime is the one of interest in this paper, and that it is characterized by low Reynolds numbers, the transition adapted SST model was used to account for boundary layer transition. Detailed formulation of a model of turbulence can be found in the work of Menter et al. [12] and Langtry et al [13].

Menter's TransitionSST turbulence model was first detailed in [11] and is a model with four equations. In the standard equations of k- $\omega$ SST model a further two equations are meant to solve problems that arise in the transition zone between the laminar and turbulent region.

The intermittent transport equation are expressed as: 


$$
\frac{\partial(\rho \gamma)}{\partial t}+\frac{\partial\left(\rho U_{j} \gamma\right)}{\partial x_{j}}=P_{\gamma 1}-E_{\gamma 1}+P_{\gamma 1}-E_{\gamma 2}+\frac{\partial}{\partial x j}\left[\left(\mu+\frac{\mu_{t}}{\sigma_{\gamma}}\right) \frac{\partial \gamma}{\partial x_{j}}\right]
$$

while the transport equation for the momentum thickness Reynolds number, is:

$$
\frac{\partial\left(\rho \tilde{\operatorname{R}} e_{\theta}\right)}{\partial t}+\frac{\partial\left(\rho U_{j} \tilde{R} e_{\theta}\right)}{\partial x_{j}}=P_{\theta}+\frac{\partial}{\partial x_{j}}\left[\sigma_{\theta}\left(\mu+\mu_{t}\right) \frac{\partial \tilde{\operatorname{R}} e_{\theta}}{\partial x_{j}}\right]
$$

\section{Results and discussions}

The results of the flow simulations confirm that the flow is in transition on a significant portion of the airfoil used for the VAWT, therefore the use of the additional two transport equations of the model is justified.

In determining the influence of turbulence intensity in wind turbine efficiency vertical shaft at the start moment, we plotted in Figure 2 the power coefficient variations on a full rotation for the cases studied.

In Figure 3 we show variations of vorticity for various positions of of the wind turbine blades. Thus variations are provided for angular positions $0,120,240^{\circ}$ for the turbulent intensity values of $1 \%, 5 \%, 10 \%$ and $20 \%$.

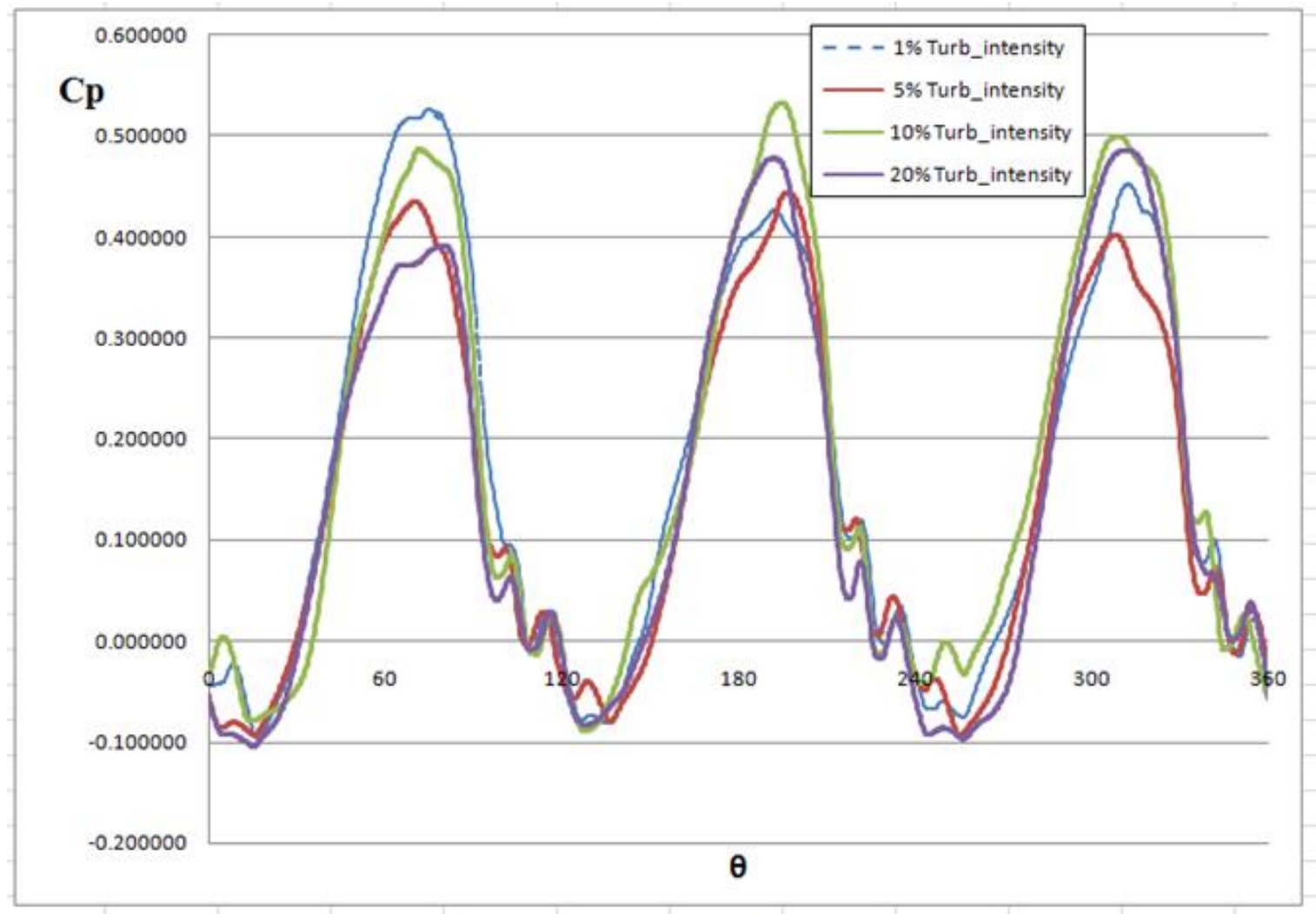

Fig. 2. The power coeficient variation

\section{Conclusions}

In this paper the influence of turbulence intensity on the efficiency of a wind turbine at the time of start was analyzed. In order to view the influence of turbulence intensity we represented the variations in different positions of the vorticity flow field around the wind turbine blades, for all cases considered. From the power coefficient variation it resulted that the farfield value of the turbulent intensity may influence the efficiency of the wind turbine (2D analysis) by up to 3 percent. The trailing wake patern is more unstable in the case of lower turbulence intensity, leading to an oscillation in the lift coefficient of the downstream blade which it impacts. As turbulence intensity increases, the wake is turbulent and the von Karman vortex street is dissipated before reaching the downstream blade. Overall, the combined effects of vortices shed by the blades upstream lead to an irregular momentum variation which adds to the main oscilatory pattern from classic theory.As seen in Fig.2, the differences in peek power coefficient are highest where the turbulence intensity is lowest, for the above reasons. 


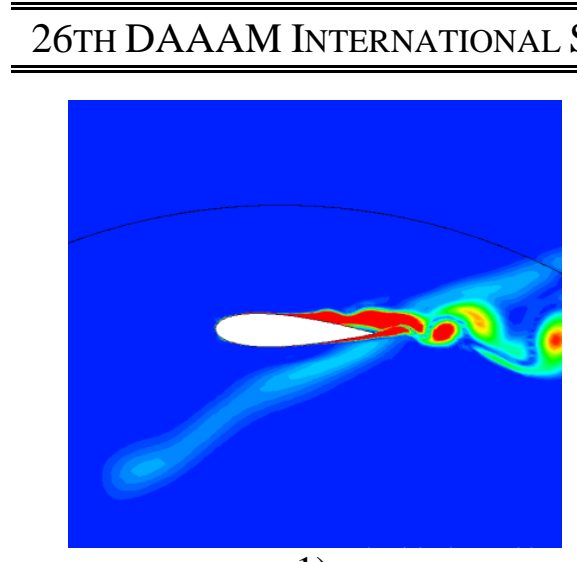

1)

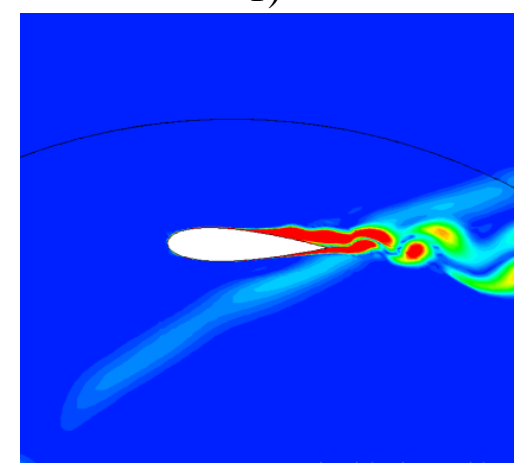

1')

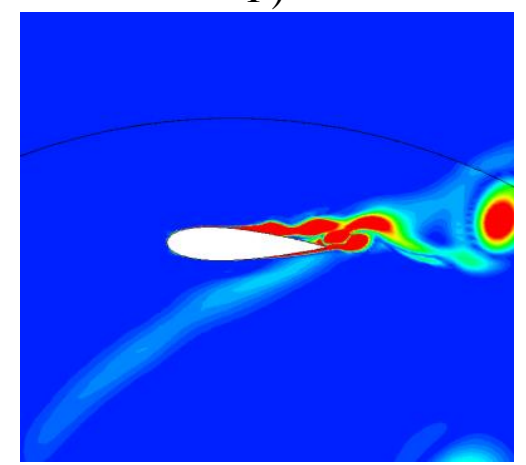

1")

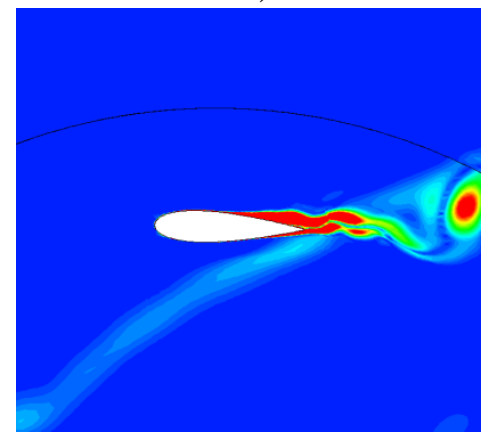

$1 " ')$

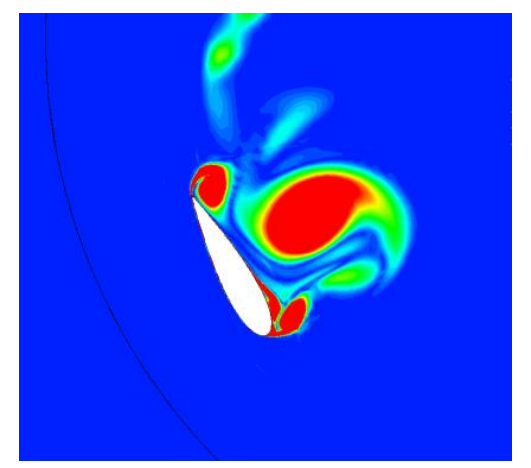

2)

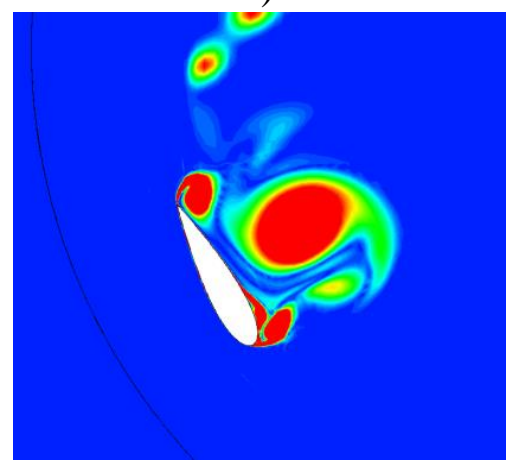

2')

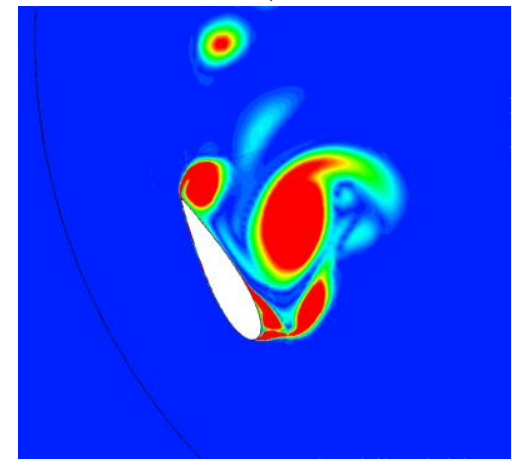

2")

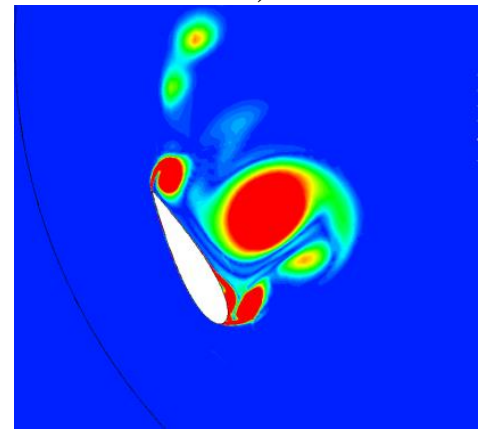

2"')

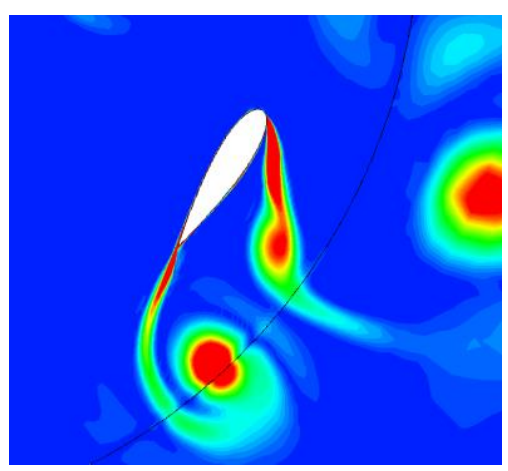

3)

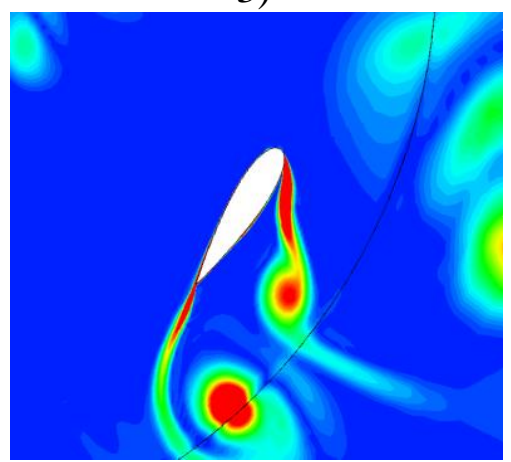

3')

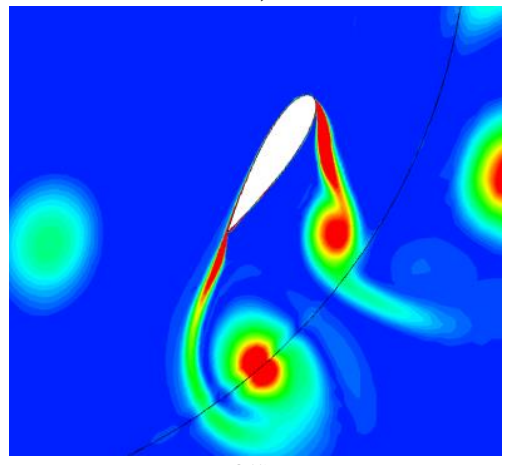

3")

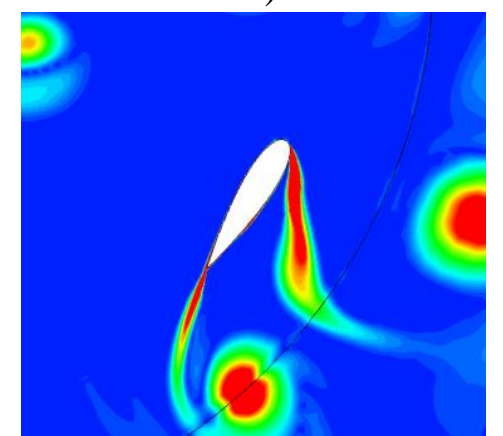

3"')

Vorticity Magnitude:

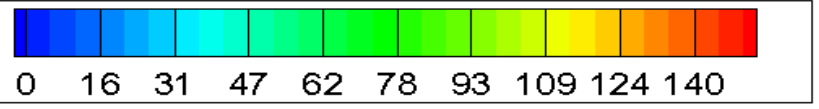

Fig. 3. The vorticity distribution for

1) Odegree position and $1 \%$ turbulence intensity; 2) 120 degree position and $1 \%$ turbulence intensity;

3) 240degree position and $1 \%$ turbulence intensity;

1') Odegree position and 5\% turbulence intensity; 2')120degree position and 5\% turbulence intensity;

3') 240degree position and 5\% turbulence intensity;

1 ") Odegree position and $10 \%$ turbulence intensity; 2 ")120degree position and $10 \%$ turbulence intensity; 3") 240degree position and 10\% turbulence intensity;

1"') Odegree position and 20\% turbulence intensity; 2"')120degree position and 20\% turbulence intensity; 3 "') 240degree position and $20 \%$ turbulence intensity; 
Moreover, on average, the maximum power coefficient is highest when the turbulence intensity is at about $10 \%$. In addition to this, the variation of the $\mathrm{Cp}$ with theta also displays an oscillation of much lower amplitude and frequency. Further work will have to make use of more advance turbulence modelling in order to confirm the results obtained herein.

\section{References}

[1] W. Tjiua, T. Marnotob, S. Mata, M. H. Ruslana, K. Sopiana, Darrieus vertical axis wind turbine for power generation II: Challenges in HAWT and the opportunity of multi-megawatt Darrieus VAWT development, Renewable Energy, Volume 75, March 2015, Pages 560-571.

[2] L. A. Danaoa, J. Edwardsb, O. Eboibic, R. Howellc, A numerical investigation into the influence of unsteady wind on the performance and aerodynamics of a vertical axis wind turbine, Applied Energy, Volume 116, 1 March 2014, Pages 111-124.

[3] E. Verkinderena, B. Imamb, A simplified dynamic model for mast design of H-Darrieus vertical axis wind turbines (VAWTs), Engineering Structures, Volume 100, 1 October 2015, Pages 564-576.

[4] P. Kacor, S. Misak, L.Prokop, Modification of construction design of vertical axis wind turbine, Annals of DAAAM for 2011 \& Proceedings of the 22nd International DAAAM Symposium, Volume 22, No. 1, ISSN 1726-9679, ISBN 978-3-901509-83-4, Published by DAAAM International, Vienna, Austria, EU, 2011.

[5] Wang S.,Tao Z. , Numerical investigation on dynamic stall associated with low Reynolds number flows over airfoils, 2nd International Conferance on Computer Engineering and Technology,2010.

[6] Paraschivoiu, I., Saeed, F., \& Desobry, V., "New Algorithms for Wind Turbine Performance Prediction and Optimal Design" Papier The 20th International Symposium on Transport Phenomena, Victoria, BC, Canada(2009), , Victoria.

[7] Saeed, F., Paraschivoiu, I., Paraschivoiu, M., Hess, M., \& Gabrys, C., "Inverse Airfoil Design Method for Improved Performance of VAWT" Papier WINDPOWER 2010 Conference \& Exhibition, Dallas, Texas, USA., États-Unis, Texas, Dallas, 2010-05-21

[8] S. Armstrong, A. Fiedler, S. Tullis, Flow separation on a high Reynolds number, high solidity vertical axis wind turbine with straight and canted blades and canted blades with fences, Renewable Energy, Volume 41, May 2012, Pages 13-22.

[9] Bogateanu, R. (2010). Aerodynamic Performance Prediction of Darrieus Wind Turbines, Annals of DAAAM for 2010 \& Proceedings of the 21 st International DAAAM Symposium, 20-23rd October 2010, Zadar, Croatia, ISSN 1726-9679, ISBN 978-3-901509-73-5, Katalinic, B. (Ed.), pp. 1213-1214, Published by DAAAM International Vienna, Vienna.

[10] I. Mălăel, V. Drăgan, G. Vizitiu, The vertical axis wind turbine efficiency evaluation by using the cfd methods, Applied Mechanics and Materials, ISSN 1662-7482, Vol. 772, Cap.2,pp. 90-95, 2015.

[11] Menter, F. R., Esch, T. and Kubacki, S., Transition Modelling Based on Local Variables, 5th International Symposium on Turbulence Modeling and Measurements, Spain, 2002.

[12] F. MENTER,J. C. FERREIRA,T. ESCH,B. KONNO, The SST Turbulence Model with Improved Wall Treatment for Heat Transfer Predictions in Gas Turbines, Proceedings of the International Gas Turbine Congress 2003 Tokyo November 2-7, 2003.

[13] R.B. Langtry,F.R. Menter, Transition Modeling for General CFD Applications in Aeronautics, AIAA $2005-522$. 